\title{
Yod
}

Revue des études hébraïques et juives

19 | 2014

Aharon Appelfeld, cinquante ans d'écriture

\section{Aharon Appelfeld et quelques contemporains}

Aharon Appelfeld \& his Contemporaries

אהרון אפלפלד וסופרים נוספים בני זמנו

\section{Helena Shillony}

\section{OpenEdition}

\section{Journals}

Édition électronique

URL : https://journals.openedition.org/yod/1993

DOI : 10.4000/yod. 1993

ISSN : 2261-0200

Éditeur

INALCO

Édition imprimée

Date de publication : 30 mai 2014

ISBN : 978-2-85831-214-6

ISSN : 0338-9316

Référence électronique

Helena Shillony, "Aharon Appelfeld et quelques contemporains », Yod [En ligne], 19 | 2014, mis en ligne le 16 avril 2014, consulté le 08 juillet 2021. URL : http://journals.openedition.org/yod/1993 ; DOI : https://doi.org/10.4000/yod.1993

Ce document a été généré automatiquement le 8 juillet 2021.

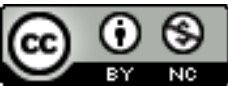

Yod est mis à disposition selon les termes de la Licence Creative Commons Attribution - Pas d'Utilisation Commerciale 4.0 International. 


\title{
Aharon Appelfeld et quelques contemporains
}

\author{
Aharon Appelfeld \& his Contemporaries
}

אהרון אפלפלד וסופרים נוספים בני זמנו

\author{
Helena Shillony
}

La génération d'Aharon Appelfeld est arrivée à l'âge adulte dans les premières décennies de l'État d'Israël. Le jeune État a accueilli des milliers d'enfants et d'adolescents, orphelins ou sans famille, victimes de la Shoah, et les a placés dans des kibboutzim et des fermes pour les former et en faire des agriculteurs. Certains d'entre eux sont devenus écrivains et ont relaté dans des romans et des nouvelles leurs expériences pendant la guerre et la vie des jeunes survivants en Israël. On peut citer à titre d'exemple Shammaï Golan, né en 1933 en Pologne, un écrivain oublié aujourd'hui, mais qui a été célèbre dans les années soixante et soixante-dix. Il faut également mentionner Ouri Orlev, connu pour ses livres pour la jeunesse, qui avoue qu'il lui est plus facile d'évoquer la Shoah du point de vue de l'enfant qu'il a été. L'arrivée en Israël a confronté ces jeunes à une société dont l'idéologie s'opposait violemment à la diaspora dont ils venaient. Il n'y avait pire insulte à l'époque que galuti c'est-à-dire caractéristique de la galut, la diaspora. Cette tendance forte et dominante a imposé des choix à ces nouveaux Israéliens et dans cet article, je voudrais comparer les solutions qu'ils ont adoptées à celles d'Aharon Appelfeld qui dès le début a choisi une voie particulière. Je me permettrai de mêler les biographies aux œuvres littéraires, approche difficile à éviter lorsqu'il s'agit d'autobiographies ou de romans autobiographiques d'une génération marquée et mutilée par ce que Georges Perec a appelé « l'Histoire avec sa grande hache $»^{1}$, expression qui s'impose bien qu'elle soit devenue un cliché. Je voudrais ajouter aux œuvres des écrivains reconnus le roman biographique récent de la jeune écrivaine Roni Sarig במהרה תישוב רוח («Le vent soufflera bientôt ») où elle raconte la vie d'un homme qu'elle connaît bien, enfant pendant la Shoah, membre du kibboutz Yagour et officier supérieur en Israël. Au crépuscule de sa vie, il se souvient de tout ce qu'il a dû refouler pendant des années pour se conformer à l'idéal du sabra héroïque et impassible. Il n'était pas le seul. À 
l'occasion du jour de la Shoah, le quotidien Yedioth Ahronoth a publié le 20 avril 2012 les interviews d'une dizaine de pilotes de guerre, tous âgés aujourd'hui de plus de soixante-dix ans. Orphelins pour la plupart, ils avaient tout fait pour s'assimiler à la société israélienne et se distinguer dans l'armée. Quant à leur passé pendant la Shoah : "Nous avons décidé de nous taire ", disent-ils. Certains apprennent seulement grâce aux questions du journaliste que le sort des camarades qu'ils croyaient connaître depuis des années avait été semblable au leur.

2 Quelle identité assumer dans la nouvelle vie ? D’abord quel nom ? Georges Perec nous a appris l'importance du nom de famille, dans un registre sérieux dans $W$ ou le souvenir d'enfance où il analyse longuement le sien et sur le mode ludique dans Quel petit vélo à guidon chromé au fond de la cour ?² Dans les premières décennies de l'État d'Israël, il était d'usage d'hébraïser les noms de famille d'origine allemande, slave ou arabe. Ben Gourion avait imposé le changement de nom aux diplomates et aux fonctionnaires qui représentaient le jeune pays, mais la mode s'est étendue à toute la population. Quel meilleur moyen d'effacer le passé diasporique méprisé, de créer « un nouveau Juif »? L'auteur Shammaï Golan est né Goldstein et a remplacé ce nom par un nom hébreu. Les protagonistes de son roman La mort d'Ouri Peled préfèrent des noms hébraïques symboliques. Le jeune rescapé Yossélé-Jozek Kupferman deviendra Ouri Peled, nom tiré du mot plada, acier, pour symboliser la force. L'adolescent venu d'ailleurs arrive à faire la conquête de la belle Osnath, prénom typiquement israélien. Son beau-père, un des fondateurs du kibboutz qui a accueilli les jeunes rescapés, s'appelle Barzilaï (de barzel, fer). Un des invités au mariage s'étonne de cette alliance insolite :

מי מילל ומי פילל:אחד יוזק קופרמן נושא לאשה את אסנת ברזילי.ימות המשיח!

Un Jozek Kupferman épouser une Osnath Barzilaï ? Qui l'eût cru ? Le Messie doit être venu ${ }^{3}$

3 Lorsque Peled rencontre Henia, une jeune femme qui, comme le veut la tradition, porte le nom de sa grand-mère, il se rend compte de la solution de continuité entre les générations qu'implique la nouvelle identité israélienne qu'il a assumée :

הניה שמך" נחרד לפתע, "אצלנו מחליפים שמות של חוץ לארץ, חייבים!" הגביה קולו כתובע עלבון נשכח."

"Tu t'appelles Henia », s'exclama-t-il soudain, « chez nous on change ces noms qui viennent d'ailleurs, il le faut ! ». Il élevait la voix comme s'il voulait se plaindre d'une humiliation oubliée ${ }^{4}$.

4 Ouri Orlev est né Jerzy (Jurek) Orlowski en Pologne. Il a d'abord changé de prénom pour adopter un prénom hébreu très courant à l'époque. Son premier livre, 'Ad mahar (" Jusqu'à demain »), roman autobiographique publié en 1958, était signé Ouri Orlowski. Mais l'auteur des livres qui suivront s'appellera désormais Ouri Orlev, nom phonétiquement proche d'Orlowski, composé de deux mots hébreux Or et Lev, lumière et cœur, et c'est sous ce nom qu'il se fera connaître. Même Amos Oz, un sabra, né Amos Klausner à Jérusalem, mais qui a passé son adolescence dans un kibboutz, choisit un nom héroïque qui veut dire force, audace.

5 Ces choix étaient souvent, surtout pour les prénoms, imposés par des instituteurs ou des moniteurs qui préféraient des noms familiers aux noms étrangers, phénomène bien connu dans les pays qui accueillent des immigrants. Quant au changement des noms de famille, il était motivé par le désir de s'intégrer à la société israélienne. Les noms choisis étaient souvent bibliques ou des noms qui, contrairement à la réputation de faiblesse des Juifs de la diaspora, dénotaient la force et le courage. Dans ce contexte, il est intéressant de voir le comportement adopté par Appelfeld. Le prénom que lui 
avaient donné ses parents était Erwin, qui a été remplacé par le prénom hébreu Aharon. Erwin resurgit, soixante ans après sa disparition, dans le roman publié en 2010 האיש שלא פסק לישון Le garçon qui voulait dormir)5. Dans cette œuvre, Erwin se voit comme celui qui réalise la vocation d'écrivain de son père et il assume pleinement son patronyme qu'il rendra célèbre. Appelfeld est resté Appelfeld, ce qui n'était pas évident à l'époque. On imagine facilement un employé de l'Agence juive lui imposant la traduction en hébreu de son nom allemand («champ de pommiers», Tapouhi en hébreu). Appelfeld a résisté à la tentation conformiste, il a refusé de trancher les liens qui l'attachaient à sa famille et à son passé .

Un autre trait important qui différencie Appelfeld de ses contemporains est son choix insolite d'études universitaires. Appelfeld opte pour le yiddish qui avait été avant la guerre la langue rivale de l'hébreu. Avec la disparition des millions d'hommes qui l'avaient parlé, l'hébreu n'avait plus rien à craindre. Le yiddish était devenu la langue des disparus, la langue des vieux, la langue d'un passé qu'on s'efforçait d'oublier dans le jeune État. Appelfeld commence des études de yiddish à l'Université hébraïque de Jérusalem. Que choisissaient ses contemporains, marqués comme lui par la Shoah? Certains d'entre eux, grâce au service militaire obligatoire, se distinguaient dans l'armée. C'était la consécration définitive du nouvel Israélien, ce qui arriva à Shammaï Golan lui-même et à son protagoniste Ouri Peled ainsi qu'au personnage bien réel Israël Levin dont Roni Sarig nous raconte l'histoire. Levin devint un personnage important dans l'armée et au ministère de la Défense et resta toute sa vie membre du kibboutz qui l'avait accueilli. Golan et son héros abandonnent leur carrière militaire pour faire des études d'histoire et de littérature hébraïque. Un autre sujet populaire à l'époque était l'archéologie biblique. Loin d'être une évasion dans le passé, c'était une profession patriotique qui légitimait la présence juive en Palestine. Yigaël Yadin qui avait servi comme chef d'état-major pendant la guerre d'Indépendance est devenu un archéologue célèbre et tout le pays suivait les fouilles qu'il menait à Massada et à Hatsor. Un camarade d'Appelfeld à Jérusalem, rescapé lui aussi de la Shoah, David Guilad, né Grinfeld, avait choisi l'archéologie. La plongée dans le passé lointain n'a pas sauvé Guilad des cauchemars du passé récent. Il s'est suicidé dans la force de l'âge.

Peut-on vraiment échapper aux traumatismes de l'enfance? Le jeune État avait tout mis en œuvre pour que ces enfants et adolescents sans famille oublient leur passé pour devenir des Israéliens sans complexes. Appelfeld savait dès le début que cette intégration était fondée sur une fraude, mirma. Il analyse ses réactions dans un bref recueil d'écrits autobiographiques מסות בגוף ראשון ("Essais à la première personne ») qui a paru en 1979, vingt ans avant Histoire d'une vie. En 1962 Appelfeld avait publié son premier recueil de nouvelles עשמ ("Fumée »), un an plus tard Golan publie son roman autobiographique באשמורת אחרונה («a relève de l'aube») où il raconte ses errances d'orphelin avant son arrivée en Israël. Ses parents étaient morts de faim et de maladie en Asie centrale. À la dernière page du roman, l'adolescent Haïmké rencontre un représentant de l'Agence juive qui fait l'éloge du kibboutz et lui promet monts et merveilles. Le roman se termine sur cet échange : 
Tu te sentiras chez toi.

Comment chez moi ? Comme à l'orphelinat à Tachkent ou en Pologne? Tu es un petit pessimiste, dit l'homme.

Qu'est-ce qu'un pessimiste?

Un pessimiste est un malade, mais nous allons te guérir ${ }^{7}$. Palestine en 1946 :

בחודש אב הגענו בתחושה נוראה שבמקרה הגענו.

Nous sommes arrivés au mois de $A v$ avec le sentiment affreux d'être là par hasard ${ }^{8}$.

Comment guérir ces jeunes pessimistes qui avaient été témoins de tant d'horreurs? On les a placés dans des kibboutzim ou des écoles d'agriculture ; ils devaient y travailler et apprendre l'hébreu. Pour la plupart, il s'agit d'une réussite: ces adolescents sont devenus des membres utiles de la société israélienne, au prix de l'oubli de leurs familles, au prix du renoncement à leur langue maternelle, le yiddish, le polonais ou l'allemand. Un cas flagrant d'échec est celui du peintre Pinchas Burstein, dit Maryan. Né en 1927, il est arrivé en Israël à dix-neuf ans, trop grand pour être envoyé dans un internat. Pire encore, aucun kibboutz ne voulait de lui, Burstein avait perdu une jambe dans la marche forcée avant la libération d'Auschwitz et ne pouvait pas travailler aux champs. Malgré les promesses qu'on lui avait prodiguées avant son départ, personne ne l'attendait à Haïfa et il passa une journée au port, assis sur une caisse d'oranges, attendant en vain qu'on vienne le chercher. Il ne le pardonna jamais et quitta Israël au bout de quelques années pour étudier à l'École des beaux-arts de Paris. Sous le nom de Maryan, il devint un peintre célèbre à Paris et aux États-Unis. Ses tableaux mettent en scène le monde concentrationnaire et monstrueux qu'il avait connu.

Ceux qui sont restés en Israël connaissent d'autres déchirements. Ouri Peled de Shammaï Golan incarne la tragédie de sa génération. Arrivé dans un kibboutz avec un groupe d'adolescents rescapés, il fera tout pour se détacher d'eux et se faire une place dans le groupe «supérieure" des sabras, enfants du kibboutz. Beau garçon, il se distingue aussi comme soldat et le fringant officier réussit à plaire à Osnath Barzilaï qui, dans cette société censée être égalitaire, représente l'aristocratie. Après leur mariage, Peled consacre ses jours et ses nuits à l'armée et Osnath, excédée, finit par le convaincre de changer de vie. Ils quittent le kibboutz et s'installent à Jérusalem où Peled va commencer des études d'histoire. Mais à Jérusalem, un changement s'opère en lui : Ouri redevient Yossélé, il découvre le charme des quartiers religieux, il fréquente des artisans orthodoxes qui lui rappellent ses grands-parents, il retrouve des souvenirs qu'il avait enfouis si profondément qu'il croyait les avoir effacés à jamais. Il rejette l'idéologie du kibboutz qui avait voulu le transformer. Il déclare, et les noms sont symboliques une fois de plus :

יהיו לי ילדים.שמותיהם יהיו כשמות ילדיו של סבי: הירשל,טוביה ,ברכה. J'aurai des enfants. Je leur donnerai les noms des enfants de mon grand-père : Hirschel, Touvia, Brakha9.

11 Les études n'intéressent Peled qu'en fonction de l'histoire récente des Juifs. L'appartement $d u$ jeune couple se trouve en face de la colline où se dressent les bâtiments de Yad Vashem et cette proximité n'est naturellement pas fortuite. Yad Vashem représente le passé qui n'a pas vraiment disparu et Ouri décidera, au grand étonnement d'Osnath et de sa famille, d'y travailler comme chercheur. Comment ose-til troquer son uniforme d'officier et les vêtements respectables d'un professeur d'histoire contre la blouse grise de l'archiviste? Pourquoi préférer un passé affreux à 
un avenir glorieux ? Le symbolisme est peut-être trop évident, mais le dilemme d'Ouri, déchiré entre le passé et le présent (sa femme qui ne le comprend plus et le trompe probablement) n'a pas de solution. Le titre du roman annonçait déjà le dénouement : la mort d'Ouri Peled. Il sera tué pendant la guerre des Six Jours dans les combats pour la conquête de la vieille ville de Jérusalem. Shammaï Golan lui-même a travaillé à Yad Vashem, il a réuni et publié des témoignages sur la Shoah.

Le roman de Roni Sarig במהרה תישוב רוח («Le vent soufflera bientôt ») est un texte hybride. Il est de style documentaire quand il rapporte fidèlement les souvenirs du ghetto du jeune Izio (diminutif polonais du prénom Israël) et ses débuts en Israël. Le livre n'est plus un témoignage quand il évoque la vie d'adulte de son héros. La narratrice, comme l'auteur, habite dans un kibboutz et elle décrit les liens qui se nouent entre elle et son voisin, un vieillard solitaire qui l'intrigue et qui finit par lui raconter son histoire. Le texte se fonde sur un va-et-vient entre différents passés. Dans la première partie, chaque chapitre correspond à une année entre 1939 et 1945, les années de la Shoah que le jeune Izio passe en Pologne. La seconde partie se passe tout entière en Israël sous le signe des guerres et de la carrière militaire d'Israël Levin. On arrive enfin à 2007, le présent où la narratrice gagne la confiance du veuf solitaire qui lui raconte sa vie. Israël Levin ne change pas de nom, son nom de famille est une variante du nom hébreu Lévi, et il ne change pas de prénom peut-être parce que son père est vivant. Il restera Sroulik, le diminutif yiddish d'Israël. En 1951 il épouse la belle Yaëla. Le jeune couple qui restera toute sa vie au kibboutz va voir les parents de la jeune femme, Nahman et Hanka, pour leur annoncer leur décision de se marier. La description de cette visite rappelle le destin d'Ouri Peled :

חנקה הגישה עוגיות לשולחן שבמרכז החדר.לא בכל יום מבקר אצלם שרוליק הזה, נולי

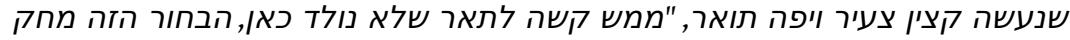

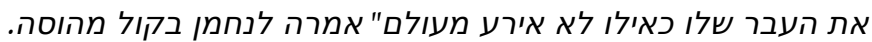
Hanka posa des biscuits sur la table qui était au milieu de la pièce. Ce n'était pas tous les jours que ce Sroulik, qui était devenu un jeune officier séduisant venait les voir. « On a de la peine à croire qu'il n'est pas né ici, ce garçon a effacé son passé comme s'il n'avait jamais existé » dit-elle à mi-voix à Nahman ${ }^{10}$.

13 Les apparences sont trompeuses: la veille du mariage, Sroulik va avec sa fiancée déterrer une boîte qu'il a cachée dans un coin du kibboutz. Elle contient un bouton, le bouton que sa mère a arraché à son manteau. Sur le chemin de l'Umschlagplatz à Varsovie, la voie qui menait aux camps et à la mort, elle lui a dit de se sauver et lui a confié ce talisman. Sroulik demande à Yaëla de coudre ce bouton à l'intérieur de sa robe de mariée. Bien qu'il a fait la conquête de Yaëla, courtisée par tous les jeunes du kibboutz, Israël Levin ne sera pas heureux en ménage. Il adore sa femme, mais lui reproche de garder ses distances, de ne pas l'aimer comme il le voudrait. Cherche-t-il l'amour maternel inconditionnel dont on l'a brutalement sevré? Yaëla et les femmes avec qui il aura de brèves aventures s'avèrent incapables de combler ce vide affectif. Au soir de sa vie, le vieillard se confie à la jeune narratrice: certes, il avait été un personnage important dans l'armée et au gouvernement, admiré et aimé, mais les années de la Shoah qu'il a cherché à refouler ne cessent de le hanter. Il raconte ses souvenirs d'enfance et le fier militaire redevient le petit Izio, marqué par la disparition de sa mère et les années d'épouvante.

Dans une interview accordée en 2011 au magazine La'isha à l'occasion de la parution de son roman מים אדירים («Les eaux tumultueuses»), Appelfeld parle de ses contemporains. On leur a enjoint d'oublier qu'ils avaient eu des parents, une ville 
natale, des grands-parents, qu'ils avaient connu des expériences horribles, mais aussi des expériences grandioses. Il fallait tout effacer. Appelfeld a refusé d'oublier. Il raconte qu'un jour, dans la salle à manger du kibboutz, il a noté sur un bout de papier des repères biographiques pour s'accrocher à la vie : «Papa Michaël, maman Bonia, grand-père Méir, je suis né à Czernowitz, dans une rue près du parc $»^{11}$. Appelfeld a gardé son nom et son passé. Il n'a pas cherché à jouer le rôle de l'Israélien modèle de sa génération, qui aurait réussi à effacer toute trace de la Shoah, qu'on aurait dit né en Israël. Dès le début, il s'est identifié avec les rescapés, avec le yiddish, il a assumé sa condition de survivant. Dans les premières décennies du jeune État, il a eu le courage de ses convictions qui ne correspondaient pas à l'idéologie de l'époque. Il n'a donc pas connu les déchirements d'un Ouri Peled, le personnage romanesque de Shammaï Golan, ou d'un Israël Levin, un homme bien vivant, le héros du livre de Roni Sarig. C'est en restant fidèle à lui-même qu'Aharon Appelfeld s'est acquis l'admiration et la fidélité de ses innombrables lecteurs.

\section{BIBLIOGRAPHIE}

APPELFELD, Aharon (1979), מסות בגוף ראשון («Essais à la première personne »), Jérusalem, Hasifria hatsionit. APPELfELD, Aharon (2010), האיש שלא פסק לישון, Or Yehuda, Kinneret, Zmora-Bitan. Trad. française : Le garçon qui voulait dormir, Paris, Éditions de L'Olivier, 2011.

APPELFELD, Aharon (2011), interview dans le magazine La'isha (30 mai 2011).

GolAN, Shammaï (1963), באשמורת האחרונה ("La relève de l'aube »), Tel Aviv, Massada. Golan, Shammaï (1971), מותו של אורי פלד («La mort d'Ouri Peled»), Tel Aviv, Am Oved. PEREC, Georges (1966), Quel petit vélo à guidon chromé au fond de la cour ?, Paris, Denoël. PEREC, Georges (1975), W ou le souvenir d'enfance, Paris, Denoël.

SARIG, Roni (2011), במהרה תישוב רוח (« Le vent soufflera bientôt »), Tel Aviv, Hakibbutz Hameuchad.

\section{NOTES}

1. Georges Perec, W ou le souvenir d'enfance, Paris, Denoël, 1975, p. 17.

2. Paris, Denoël, 1966.

3. Sh. Golan (1971), p. 30. Les traductions sont de l'auteur de l'article.

4. Ibid. p. 133.

5. Or Yehuda, Kinneret, Zmora-Bitan. Traduction française : Paris, Éditions de l'olivier, 2011.

6. À propos de cette problématique des noms, il faut mentionner un fait curieux. Il y aujourd'hui des écrivains et des artistes israéliens qui, à la recherche de leurs racines, reviennent au nom que leurs parents ou leurs grands-parents ont rejeté et l'ajoutent au nom hébraïsé. Ce phénomène est 
commun aux Ashkénazes qui veulent préserver la mémoire de leurs familles disparues dans la Shoah et aux Sépharades qui revendiquent leurs origines orientales.

7. Sh. Golan (1963), p. 261.

8. A. Appelfeld (1979), p. 59. Le mois de Av correspond à juillet-août.

9. Sh. Golan (1971), p. 137.

10. R. Sarig (2011), p. 161.

11. A. Appelfeld (2011).

\section{RÉSUMÉS}

Cet article se propose de comparer l'expérience israélienne d'Aharon Appelfeld avec celle de quelques contemporains, témoins, comme lui, des premières décennies de l'État d'Israël. Rescapés de la Shoah, confiés aux kibboutzim ou aux écoles d'agriculture qui changent leurs noms et s'efforcent d'en faire des paysans juifs en effaçant leur passé, ces adolescents, pour la plupart orphelins, cherchent leur voie. Je pense à l'écrivain Shammaï Golan, auteur de romans plus ou moins autobiographiques, né en 1933, à Israël Levin, membre du kibboutz Yagour et militaire, héros d'un roman biographique de Roni Sarig qui vient de paraître. Je mentionnerai aussi le cas du peintre Maryan (Pinchas Burstein), un peu plus âgé, né en 1927.

I would like to compare the Israeli experience of Aharon Appelfeld to that of other contemporaries who witnessed the first decades of the State. Survivors of the Shoah, confined in the Kibbutzim and agriculture schools which change their names, wipe out their past and try to turn them into Jewish peasants, these teenagers-most of them orphans-seek their path in life. Among them the writer Shammai Golan, author of autobiographical novels, born in 1933, Israel Levin, soldier and kibbutznik of Yagur, hero of a recent biographical novel by Roni Sarig, and I would add the painter Maryan (Pinchas Burstein), born in 1927.

מטרתו של המאמר הוא להשוות בין הנסיון הישראלי של אפלפלד ושל יוצרים אחרים, בני זמנו

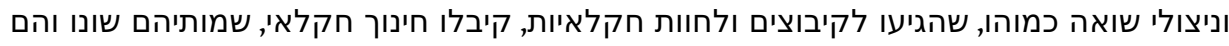

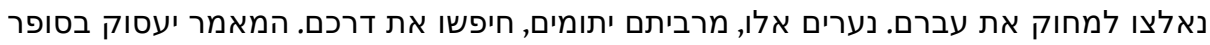

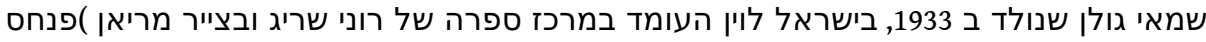

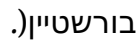


INDEX

Thèmes : littérature

Mots-clés : Appelfeld Aharon (1932-), rescapés de la Shoah, adolescents, Golan Shammaï (1933-), Sarig Roni, Maryan S. Maryan (1927-1977), La mort d'Ouri Peled

Keywords : Appelfeld Aharon (1932-), survivors of the Shoah, teenagers, Golan Shammaï (1933-), Sarig Roni, Maryan S. Maryan (1927-1977), The Death of Uri Peled, literature, Holocauste

\section{מילות מפתח}

אפלפלד, ניצולי שואה, מתבגרים, שמאי גולן, רוני שריג, מריאן ( פנחס בורשטיין), מותו: של אורי פלד.

Index chronologique : Shoah

\section{AUTEUR}

\section{HELENA SHILLONY}

Université hébraïque de Jérusalem 